\title{
CARACTERÍSTICAS FISICOQUÍMICAS, SENSORIALES, PROXIMALES Y MICROBIOLÓGICAS DE UN YOGUR CON CHOCOLATE EN REFRIGERACIÓN
}

\author{
PHYSICOCHEMICAL, SENSORY, PROXIMAL AND \\ MICROBIOLOGICAL CHARACTERISTICS OF YOGHURT WITH \\ CHOCOLATE IN REFRIGERATION
}

\author{
Ricardo A. Parra ${ }^{1 *}$ \\ Recibido para publicación: Febrero 10 de 2014 - Aceptado para publicación: Diciembre 11 de 2014

\section{RESUMEN}

\begin{abstract}
Un grupo creciente de evidencias sugiere que el consumo regular de los productos del cacao o el uso de sus principios activos como agentes terapéuticos podrían influir favorablemente en la lucha contra las enfermedades como aterosclerosis, procesos carcinogénicos, colesterol entre otras. Lo anterior es debido a los componentes nutricionales propios del chocolate, los cuales ejercen efectos positivos en el cuerpo humano. Por lo anterior es importante diversificar el consumo de chocolate a través de otros productos que sean de alta demanda en el mercado. El objetivo del trabajo fue elaborar un yogur con chocolate y evaluar las características fisicoquímicas, sensoriales, proximales y microbiológicas durante el almacenamiento en refrigeración. Para realizar la investigación se elaboró yogur en dos concentraciones,uno de ellos contenía chocolate y la otra sacarosa. Los dos tratamientos se empacaron en recipientes plástico y se evaluaron durante 30 días en condiciones de refrigeración. Durante este tiempo se evaluó pH, acidez, sinéresis, evaluación sensorial, análisis proximal y recuento de bacterias ácido lácticas Los resultados indicaron que el valor final de $\mathrm{pH}$, acidez y sinéresis fue 4,27\%; 0,95\% y $13 \%$ respectivamente. Sensorialmente el yogur con chocolate tuvo características relevantes con calificaciones por encima de 4 sobre 5, para el análisis proximal el yogur con chocolate tuvo un valor de 3,2\% superior al yogur con sacarosa. El recuento de bacterias acido lácticas indicó un aumento para las muestras con chocolate. Basándose en las características fisicoquímicas, sensoriales, proximales y microbiológicas se sugiere que la adición de chocolate puede ser considerado potencialmente un ingrediente para elaboración de yogur.
\end{abstract}

Palabras clave: acidéz, bacterias ácido lácticas, sinéresis, Streptococcus thermophilus ,Theobroma Cacao L.

\begin{abstract}
A growing body of evidence suggests that regular consumption of cocoa products or the use of active ingredients as therapeutic agents could favorably influence the fight against disease such as atherosclerosis, carcinogenic processes, cholesterol etc. This is due to the own nutritional components of the chocolate, which exert positive

\footnotetext{
${ }^{1}$ Químico de Alimentos. Magister Ciencia de los Alimentos. Docente. Universidad Pedagógica y Tecnológica de Colombia. Facultad de Ciencias Básicas. Escuela de Ciencias Químicas. Química de Alimentos. Avenida Central del norte. Tunja-Boyacá Email: ricardo.parra@ uptc.edu.co
} 
effects on the human body. Therefore it is important to diversify the consumption of chocolate through other products that are in high demand in the market. The objective of this research was manufacturing a yogurt with chocolate and evaluate the physicochemical, sensory and microbiological characteristics proximal during refrigerated storage. To perform research, yogurt was developed in two concentrations, one chocolate and one containing sucrose. The two treatments were packed in plastic containers and were evaluated 30 days under refrigeration. During this time $\mathrm{pH}$, acidity, syneresis, sensory evaluation, analysis proximal and count of lactic acid bacteria were evaluated. The results indicated that the final $\mathrm{pH}$, acidity and syneresis was 4,27; $0,95 \%$ and $13 \%$ respectively. Sensory yogurt with chocolate was relevantcharacteristics with scores above 4 out of 5 for the analysis proximal chocolate yogurt had a value of $3.2 \%$ above the yogurt with sucrose. lactic acid bacteria counts indicated an increase for samples with chocolate. Based on physic-chemical, sensory, proximal and microbiological characteristics it is suggested that the addition of chocolate can be considered a potential ingredient for yoghurt making.

Key words: acidity, lactic acid bacteria, syneresis, Streptococcus thermophilus ,Theobroma Cacao L

\section{INTRODUCCIÓN}

El yogur es una leche fermentada de alto consumo en todo el mundo y uno de los más populares y distribuidos derivados lácteos (Sodini et al. 2005; Saint-Eve et al. 2008; Fadela et al. 2009; Hussain et al. 2009). El Codex Alimentarious define el yogur como leche coagulada que resulta de la fermentación ácido láctica de leche entera ó descremada (Adolfsson et al. 2004; Blanco et al. 2006); además de ser un producto fermentado semisólido (Hui 1993; Noni et al. 2004; Elli et al. 2006) de apariencia viscosa, textura suave y un sabor placentero, suavemente ácido (Kumar y Mishra 2004; Salvatierra et al. 2004; Ruiz y Ramírez 2009) viene mezclado con una combinación simbiótica de Streptococcus thermophilus (ST) y Lactobacillus delbruekiisub. Bulgaricus (LB) (Noni et al. 2004; Mahmood et al. 2008) o suplementado con bacterias opcionales no patógenas (Hui 1993).

El yogur contiene mayor biodisponibilidad de nutrientes que la leche (Hui 1993); es importante destacar el incremento de la digestibilidad de la proteína y de la grasa, debido a ciertas reacciones de predigestión durante la fermentación (Kumar y Mishra 2004). Comparado con la leche, es más nutritivo en términos de contenido de vitaminas, digestibilidad y como fuente de calcio y fósforo (Zahoor et al. 2003); su composición depende del tipo de leche de la cual proviene y de una gama de factores estacionales, como: leche entera o leche descremada, estación del año, periodo de lactación y modo de alimentación del bovino (Adolfsson et al. 2004; Hussain et al. 2009).

Existen estudios científicos que han caracterizado los atributos saludables de yogur, tales como: supresión de patógenos endógenos, control de síndrome de colon irritable, reducción de factores de riesgo para cáncer, control inflamatorio de enfermedades, inmunidad innata, disminución de colesterol, alivio de síntomas de alergias, mejoramiento de la tolerancia a la lactosa e inhibición de crecimiento de Helicobacter pylori (Parra 2012).

El cacao (Theobroma cacao L., Sterculiaceae) es un árbol cuyo fruto contiene 30 ó 40 semillas que tostadas, molidas y mezcladas 
con azúcar, vainilla y canela constituyen el chocolate (Gutiérrez 2002). Este árbol crece principalmente en África, Asia, América central y del sur (Yanus et al. 2014), su nombre científico es Theobroma cacao L. y fue Carlos Linneo quien clasificó la planta. El Theobroma cacao es un árbol de 4-8 m de alto de la familia Sterculiaceae, nativo de las regiones tropicales de América, con semillas que contienen una cantidad significativa de grasas (40-50\%) y polifenoles (alrededor del 10\% del peso del grano seco) (Tinoco y Ospina 2010).

El consumo de cacao inicialmente y de chocolate posteriormente, siempre se asoció con beneficios para la salud, tales como: aportar mayor fortaleza, vigor sexual, resistencia al trabajo duro y a las bajas temperaturas (Valenzuela 2007), inhibición de los procesos carcinogénicos (Gutiérrez 2002), efecto antioxidante en la prevención y desarrollo de patologías de estrés oxidativo que incluyen enfermedades cardiovasculares y cerebro vasculares. De esta forma, el consumo de antioxidantes de origen natural constituye, actualmente una recomendación a toda edad y particularmente en la edad y en la senescencia (Valenzuela 2007), además de lo anterior, el chocolate es una fuente de energía altamente nutritiva, ya que contiene aproximadamente $30 \%$ de grasa, $6 \%$ de proteínas, $61 \%$ de carbohidratos y un 3\% de humedad, además contiene minerales (fósforo, calcio, hierro) y aporta vitaminas A y del complejo B (Valenzuela 2007) a lo anterior se suma un metabolismo rápido y buena digestibilidad (Nilva et al. 2006).

Respecto al alto contenido de antioxidantes que contiene el chocolate, como son los flavonoides, catequinas, epicatequina, procianidinas y polifenoles, estos tienen efectos en la prevención de enfermedades infecciosas (Yanus et al. 2014; Erdem et al. 2014), control en la producción del óxido nítrico que es de vital importancia para regulación de la presión arterial y el flujo de la sangre, disminución de colesterol y en mujeres de la tercera edad mostraron que el chocolate puede mejorar la osteoporosis (Yanus et al. 2014).

Estudios in vitro e in vivo también indican que el chocolate podría ser un importante medio de reducir el riesgo de enfermedades cardiovasculares y algunos tipos de cáncer, por su capacidad de controlar reacciones claves implicadas en la oxidación de las LDL o de daños oxidativos al ADN (Gutiérrez 2002).

En la actualidad se buscan nuevas alternativas en la utilización de aditivos que permitan obtener mejores características fisicoquímicas, sensoriales y nutricionales en los productos lácteos. El yogur es un alimento con alto valor nutricional con una amplia difusión en su consumo a nivel mundial. Debido a esto, en los últimos años se han buscado alternativas para mejorar las características de este producto (Parra et al. 2011).

Es por lo anterior que el objetivo de este trabajo fue elaborar un yogur con chocolate y evaluar las características fisicoquímicas, sensoriales, proximales y microbiológicas durante el almacenamiento en refrigeración.

\section{MATERIALES Y MÉTODOS}

Localización del experimento. La investigación tuvo lugar en los laboratorios de Química de 
alimentos de la Universidad Pedagógica y Tecnológica de Colombia, sede Tunja.

Materiales. Las materias primas utilizadas en la elaboración de yogur fueron:

Chocolate: Se obtuvo en forma de polvo adquirido de marca nacional y posteriormente se fundió en baño maría.

Leche: Se utilizó leche liquida entera ultrapasterizada de marca reconocida.

Leche en polvo: Se utilizó leche entera de marca reconocida obtenida en el mercado local.

Cultivo iniciador: El cultivo iniciador liofilizado conteniendo los microorganismos Lactobacillus delbrueckii subsp. Bulgaricus y Streptococcus thermophilus fueron adquiridos de marca Vivolac ${ }^{\circledR}$ disponible en el mercado.

Sacarosa: Se adquirió en el mercado local de marca reconocida.

Preparación del cultivo iniciador. Para la preparación del cultivo se utilizó la metodología propuesta por Sori y Baba (2012), con algunas modificaciones. En la preparación del cultivo se utilizó una cabina de flujo laminar horizontal doble, sterilof modelo CFD-2000.

El cultivo iniciador para la elaboración del yogur fue preparado al pre calentar leche ultrapasterizada a $41{ }^{\circ} \mathrm{C}$. Una mezcla de cultivo liofilizado de marca reconocida que contenía Streptococcus thermophillus y Lactobacillus bulgaricus fue mezclado con la leche precalentada anteriormente y utilizado posteriormente para la inoculación.

Elaboración de yogur. Para la elaboración del yogur se tuvo en cuenta la metodología desarrollada por Zare et al. (2011) con algunas modificaciones como se muestra en la figura 1. Se manejaron dos tratamientos para la elaboración de yogur, un control que contenía $10 \%$ de sacarosa y un segundo tratamiento que contenía $6 \%$ de chocolate basándose la concentración utilizada en ensayos previos a este estudio.

Es importante notar que la incubación de yogur para ambos tratamientos se detuvo hasta que las muestras alcanzaron un $\mathrm{pH}$ en un intervalo entre 4 y 4,5; valores recomendados por Olson y Aryana (2008) y Briceño et al. (2001) en sus investigaciones relacionadas con yogur. Las muestras se almacenaron en condiciones de refrigeración a $4{ }^{\circ} \mathrm{C}$ en recipientes de plástico con tapa hermética del mismo material durante un periodo de 30 días; los días 1, 3, 9, 21 y 30 de almacenamiento se evaluó $\mathrm{pH}$, acidez titulable y sinéresis.

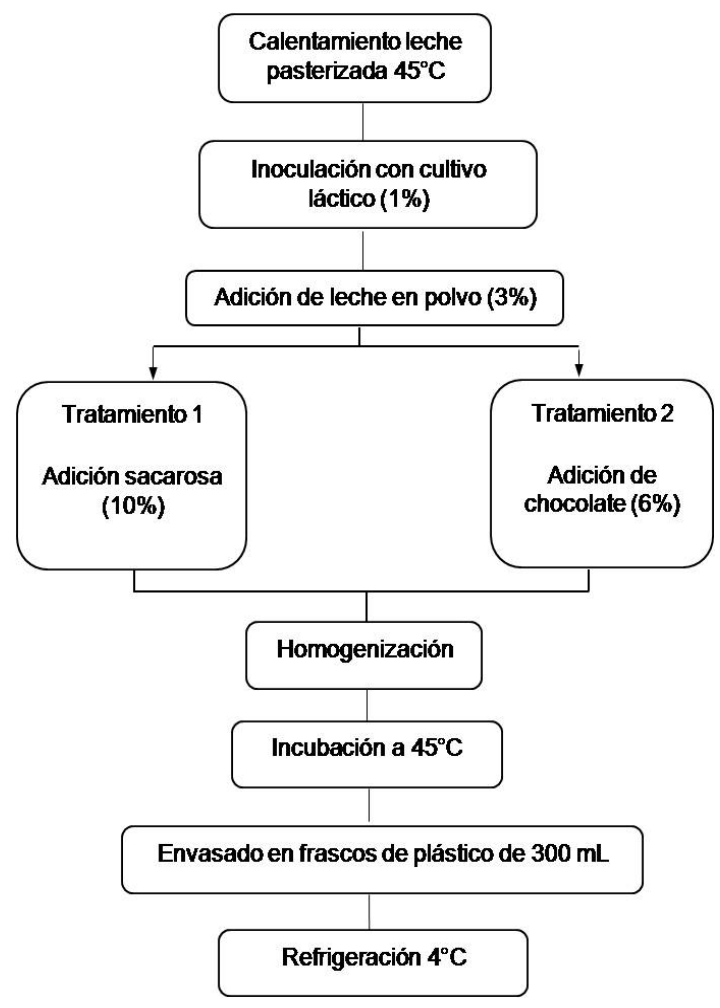

Figura 1. Elaboración de yogur (Zare et al. 2011) 
Además se realizó análisis sensorial, análisis proximal y recuento de bacterias ácido lácticas.

\section{Métodos}

\section{Caracterización fisicoquímica.}

Sinéresis: Para esta determinación se utilizó una centrífuga modelo Rotina 46. Se pesaron $20 \mathrm{~mL}$ de cada una de las muestras de yogur y se sometieron a centrifugación por un tiempo de 20 minutos a una velocidad de 4000 rpm. Luego de la centrifugación se obtuvieron los mililitros del sobrenadante (lactosuero) y se calculó el grado de sinéresis mediante la relación entre el volumen del sobrenadante y el volumen de la muestra (Charoenrein et al. 2008). El porcentaje de sinéresis fue determinado en los días 1, 3, 9, 21 y 30 bajo condiciones de refrigeración.

Acidez titulable: La acidez titulable fue medida por titulación de $10 \mathrm{~mL}$ de muestra con $0,1 \mathrm{~N}$ de $\mathrm{NaOH}$ y utilizando fenolftaleína como indicador. El resultado se expresó como porcentaje de ácido láctico (962.12/90 de la AOAC). Esta determinación se realizó los días 1, 3, 9, 21 y 30 en condiciones de refrigeración $4{ }^{\circ} \mathrm{C}$

pH: El pH del yogur fue medido con un $\mathrm{pH}$ metro digital SCHOTT CG-842 durante los días 1, 3, 9, 21 y 30 en condiciones de refrigeración $4{ }^{\circ} \mathrm{C}$. El electrodo fue calibrado con soluciones buffer 7 y 4. (945.27/90 de la AOAC).

\section{Conteo de células viables ácido lácticas en yogur.}

Preparación de la muestra. Las muestras de yogur ( $1 \mathrm{~mL}$ ) fueron individualmente mezcladas con $9 \mathrm{~mL}$ de agua peptonada. La mezcla fue agitada y se preparó diluciones $10^{-1}, 10^{-2}, 10^{-3}$, $10^{-4}$ y $10^{-5}$.
Enumeración de bacterias acido lácticas utilizando el método vertido en placa. Las bacterias ácido lácticas fueron enumeradas según método descrito por Kailasapathy et al. (2008) con algunas modificaciones. El agar utilizado fue Man, Rogosa y Sharpe (MRS Scharlau ${ }^{\circledR}$ ) la solución fue esterilizada en autoclave seguido por enfriamiento a $45{ }^{\circ} \mathrm{C}$. una vez fundido $(15 \mathrm{~mL}$ ) fue colocado en cajas de Petri. El yogur diluido apropiadamente (1 mL) fue transferido en agar MRS fundido. Se mezcló suave y uniformemente la mezcla. Las caja de Petri fueron selladas con parafina y se dejaron a temperatura ambiente para permitir que el agar se solidificara. Posteriormente, las placas se invirtieron y se colocaron en incubadora a $37^{\circ} \mathrm{C}$ por 48 horas.

\section{Caracterización proximal.}

Se seleccionó una muestra de yogur control y una muestra de yogur con chocolate para realizar los siguientes análisis cada uno por duplicado:

Determinación de humedad: Se llevó a cabo por el método gravimétrico 930.15/90 de la AOAC (1990).

Determinación de cenizas: Se realizó siguiendo el método 942.05/90 de la AOAC (1990), secando previamente las muestras a $110{ }^{\circ} \mathrm{C}$ y posteriormente calcinadas a una temperatura de $550{ }^{\circ} \mathrm{C}$, hasta peso constante.

Proteína: Se efectúo mediante el método de Kjeldalh de acuerdo a la técnica 955.04/90 (AOAC 1990), el cual determinó la concentración de nitrógeno presente en la muestra para luego ser transformado a través de un factor en proteína de 6,38.

Fibra cruda: Se tomaron muestras previamente desengrasadas y se les realizó digestión ácida en presencia de $\mathrm{H}_{2} \mathrm{SO}_{4}$ 0,255 $\mathrm{N}$ y digestión 
alcalina en presencia de $\mathrm{NaOH} 0,313 \mathrm{~N}$. Para la determinación del porcentaje de fibra cruda, fue utilizado el método Weende 962.09/90 de la AOAC (1990).

Determinación de extracto etéreo. El ensayo se realizó utilizando el método 920.39/90 de la AOAC de 1990.

Carbohidratos: Se determinó por diferencia.

\section{Evaluación sensorial .}

Para evaluar si la adición de chocolate incidía en los diferentes atributos sensoriales del yogur, como son el color, olor, sabor, viscosidad y calificación global. Se seleccionó muestra de yogur control y yogur con chocolate. Para ello se seleccionó un grupo de 30 personas no entrenadas, empleándose una prueba descriptiva por calificación de escalas de intervalo según la norma NTC 2680 del 07 de marzo de 1990. La escala de intervalo empleada para la evaluación sensorial de las muestras de yogur fue 1: me disgusta muchísimo; 2: me disgusta moderadamente; 3 : no me gusta ni me disgusta; 4: me gusta moderadamente; 5: me gusta muchísimo.

\section{Diseño experimental.}

Se utilizó un diseño experimental al azar de un solo factor, donde la respuesta a medir fue el pH, acidez, sinéresis, evaluación sensorial, proximal y recuento de bacterias ácido lácticas. Los resultados son presentados con la desviación estándar de las determinaciones por duplicado. El tratamiento de los resultados se realizó mediante análisis de varianza ANOVA en el paquete estadístico Excel Windows vista (Microsoft Office).

\section{RESULTADOS Y DISCUSIÓN}

\section{Comportamiento de acidez y $\mathrm{pH}$. \\ Acidez}

En la figura 2 se observa el comportamiento de la acidez de yogur control y yogur con chocolate durante el almacenamiento en refrigeración. La acidez en ácido láctico del yogur control tuvo promedio durante el almacenamiento $0,77 \%$ mientras que el yogur con chocolate la acidez fue en promedio 0,88\%. Se observa además, que la acidificación para la muestra de yogur con chocolate fue mayor en comparación

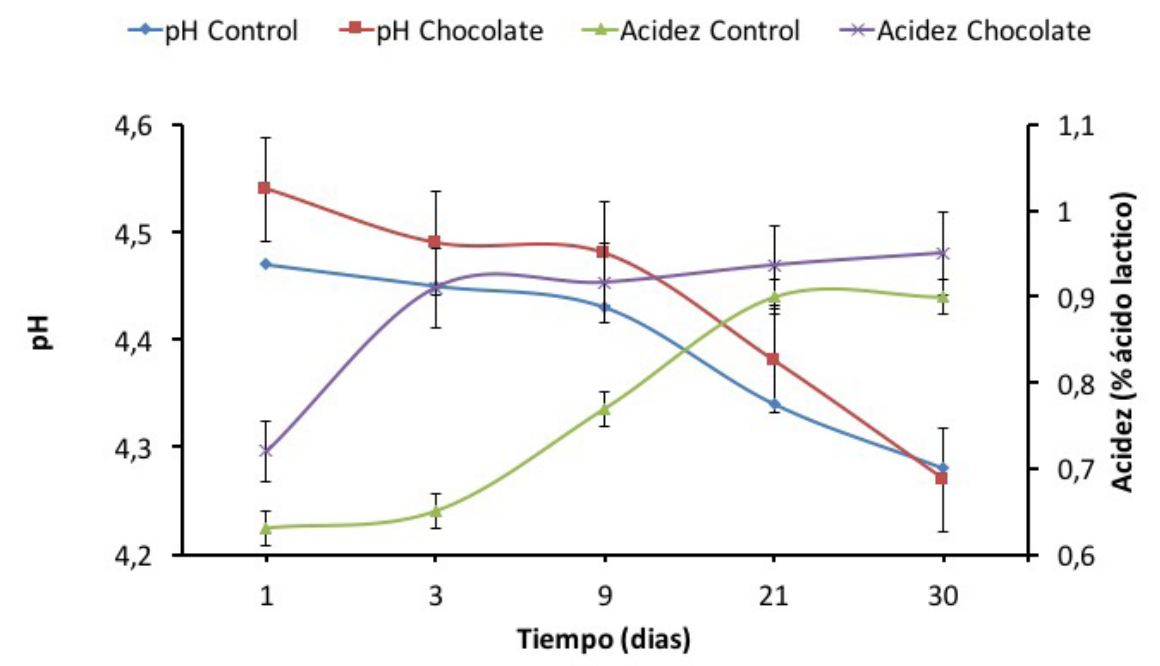

Figura 2. Comportamiento de $\mathrm{pH}$ y acidez durante el almacenamiento de yogurt control y yogurt con chocolate 
con las muestra control, lo que indica que la producción de acido láctico fue mayor por parte de las BAL en presencia de chocolate; en la muestra de yogur con chocolate a partir del día 3 de almacenamiento la acidez permaneció casi constante con valores en porcentaje de 0,91 \pm 0,08 de ácido láctico.

Los cambios anteriores pueden atribuirse a una hidrólisis de los componentes del chocolate, como también, a los posibles cambios bioquímicos presentes en el yogur durante el almacenamiento. Al respecto Briceño et al. (2001), indican que durante el almacenamiento de un yogur sin la adición de chocolate, la acidez aumentó en condiciones de refrigeración máximo hasta 1,5\% expresada en acido láctico. Igualmente, Hussain et al. (2009) encontraron en un yogur natural al final del experimento en el día 10 de almacenamiento una acidez como máximo de 1,44\% en ácido láctico.

Probablemente el chocolate estimuló el metabolismo de las BAL para la producción de ácido láctico a través de la ruta de la glucólisis durante la incubación y posterior almacenamiento de yogur, lo anterior explicaría la diferencia de comportamiento entre el yogur control y el yogur con chocolate durante el almacenamiento.

\section{pH}

En la figura 2 se observa el comportamiento del $\mathrm{pH}$. El promedio para la muestra que contenía chocolate fue 4,43 y para las muestras de yogur control fue 4,39 durante el almacenamiento; además se observa que al final del experimento, el $\mathrm{pH}$ final fue igual para los dos tratamientos. En los dos tratamientos se presentó una disminución de $\mathrm{pH}$, lo anterior pudo atribuirse a que durante el almacenamiento en condiciones de refrigeración, ocurrió una actividad microbiana por parte de las bacterias ácido lácticas presentes en el yogur tal y como lo señala Lubbers et al. (2004) en yogur almacenados durante más de 20 días bajo refrigeración.

Al respecto, en otros estudios realizados por Sahan et al. (2008); Ruiz y Ramírez (2009) y Olson y Aryana (2008) utilizando Lactobacillus acidophilus en la elaboración de yogur y leche descremada reportaron que el $\mathrm{pH}$ de yogur disminuía durante el almacenamiento en condiciones de refrigeración entre 3,8 y 4,5. Al respecto, Hassan y Amjad (2010) mencionan que la reducción de $\mathrm{pH}$ en el yogur puede ser por la degradación de la lactosa en ácido láctico, esta disminución de $\mathrm{pH}$ durante el almacenamiento se ve reflejada en la acidificación.

De acuerdo a otras investigaciones realizadas por Kailasapathy et al. (2008), los cambios bajos de $\mathrm{pH}$ son debido además a cambios en el contenido de ácido en el yogur, en este caso ácido láctico.

En la tabla 1 se observa que no existe evidencia estadística para afirmar que los parámetros fisicoquímicos influyan en el almacenamiento del yogur.

\section{Comportamiento de sinéresis}

En la figura 3 se describe el comportamiento de la sinéresis para los dos tratamientos; es notable que el yogur con chocolate tuvo un efecto en la reducción de la sinéresis durante el almacenamiento; la diferencia de la sinéresis en las dos muestras es muy amplia 
Tabla 1. Análisis de varianza para análisis físico químico

\begin{tabular}{lccccc}
\hline \multicolumn{1}{c}{$\begin{array}{c}\text { Fuente de } \\
\text { variación }\end{array}$} & Grados de libertad Suma de cuadrados & Cuadrado medio & $\mathbf{F}_{\text {calculado }}$ & $\mathbf{F}_{\text {calculado }}$ \\
\hline Total & 5 & 578,39 & 115,67 & & \\
Tratamientos & 1 & 78,12 & 78,12 & 0,97 & 18,51 \\
Interacción & 2 & 340,77 & 170,38 & 2,13 & 19 \\
Error & 2 & 159,5 & 79,75 & & \\
\hline
\end{tabular}

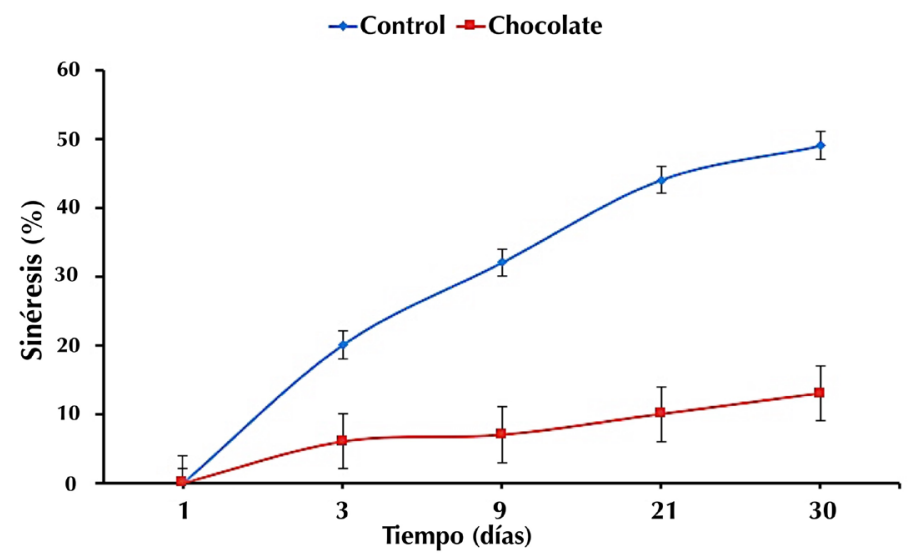

Figura 3. Comportamiento de la sinéresis durante el almacenamiento de yogurt control y yogurt con chocolate

al final del almacenamiento, $13 \%$ y $49 \%$ para el yogur con chocolate y yogur control respectivamente. Al respecto Díaz et al. (2004) reportó valores para sinéresis entre 45-65\% para un yogur control (sin fibra, elaborado con leche entera y sacarosa); este valor coincide con el obtenido en este estudio de $51 \%$ al final del almacenamiento para el caso de yogur control.

El grado de sinéresis para el yogur control aumentó durante el almacenamiento debido a la pérdida de estabilidad y retención de agua de los componentes de yogur (Díaz et al. 2004).

Este comportamiento puede ser explicado también por la disminución en el pH durante el almacenamiento, lo cual puede tener efecto de contracción en la matriz de la micela de caseína causando más eliminación de lactosuero (Achanta et al. 2007).

Peng et al. (2009) mencionan que el contenido de sólidos en un yogur ayudan a prevenir la separación de lactosuero, igualmente mencionan que un aumento en el contenido de proteína podría resultar en una textura fuerte con menos separación de lactosuero.

Al respecto Isanga y Zhang (2009) reportaron que altos contenidos de proteína en yogur está asociado con valores bajos de sinéresis, esta afirmación coincide con los valores de proteína en la tabla 2. 


\section{Análisis proximal}

En la tabla 2 se observa que el yogur elaborado con chocolate tuvo mayor contenido de proteína, fibra y grasa, lo anterior demuestra el valor nutricional del yogur con chocolate en comparación con el yogur control; sin embargo, el análisis estadístico indicó que no existen evidencias de que las variables proximales influyan en el almacenamiento del yogur para los dos tratamientos.

\section{Análisis sensorial}

En la tabla 3 se observa que el yogur elaborado con chocolate tuvo buena aceptación entre los panelistas en comparación con el yogur control, lo anterior indica que la adición de chocolate antes de la incubación y posterior almacenamiento de yogur proporcionó características adecuadas al producto final. Sobresale que los parámetros evaluados en el yogur con chocolate tuvieron calificaciones similares al yogur control. Lo anterior es corroborado por el análisis estadístico de la tabla 4 de la cual se analiza que no existe evidencia estadística para afirmar que la evaluación sensorial de las muestras que contenían yogur con chocolate y sin chocolate son diferentes.

\section{Análisis microbiológico}

En la tabla 5 se observa que hubo un incremento de $5,3 \times 10^{5} \pm 0,05$ a $9,4 \times 10^{5} \pm 0,19 \mathrm{UFC} / \mathrm{mL}$ en el número de bacterias ácido lácticas durante el almacenamiento en el yogur que contenía chocolate, lo anterior es debido probablemente a que el chocolate en su composición contenía proteína y sacarosa estimulando aun más el

Tabla 2. Análisis proximal de yogurt control y yogur con chocolate

\begin{tabular}{|c|c|c|}
\hline Parámetro & Yogurt control & Yogurt chocolate \\
\hline Proteína (\%) & $2,840 \pm 0,025$ & $3,2260 \pm 0,1229$ \\
\hline Grasa (\%) & $4,112 \pm 0,063$ & $7,1940 \pm 0,1045$ \\
\hline Fibra cruda (\%) & $0,249 \pm 0,026$ & $0,8548 \pm 0,2137$ \\
\hline Carbohidratos (\%) & 12,27 & 11,18 \\
\hline Cenizas (\%) & $0,692 \pm 0,014$ & $0,7409 \pm 0,003$ \\
\hline Humedad (\%) & $79,831 \pm 0,002$ & $76,79735 \pm 0,0699$ \\
\hline
\end{tabular}

Tabla 3. Evaluación sensorial de yogur con chocolate y yogur control

\begin{tabular}{|c|c|c|}
\hline Parámetro & Yogurt chocolate & Yogurt Control \\
\hline Sabor & $4,46 \pm 0,63$ & $4,53 \pm 0,74$ \\
\hline Aroma & $4,26 \pm 0,45$ & $4,6 \pm 0,56$ \\
\hline Color & $4,26 \pm 0,70$ & $4,26 \pm 0,88$ \\
\hline Cuerpo/textura & $4,53 \pm 0,51$ & $4,2 \pm 0,77$ \\
\hline Aceptación global & $4,36 \pm 0,31$ & $4,45 \pm 0,68$ \\
\hline
\end{tabular}


Tabla 4. Análisis de varianza para el análisis sensorial

\begin{tabular}{lccccc}
\hline $\begin{array}{c}\text { Origen de las } \\
\text { variaciones }\end{array}$ & Suma de cuadrados & $\begin{array}{c}\text { Grados de } \\
\text { libertad }\end{array}$ & $\begin{array}{c}\text { Promedio de los } \\
\text { cuadrados }\end{array}$ & F & Valor crítico para F \\
\hline Entre grupos & 0,00289 & 1 & 0,00289 & 0,130917 & 5,317655 \\
Dentro de los grupos & 0,1766 & 8 & 0,022075 & & \\
Total & 0,17949 & 9 & & & \\
\hline
\end{tabular}

Tabla 5. Recuento de bacterias ácido lácticas

Yogurt control (UFC/g)

\begin{tabular}{lcl}
\hline Inicio (día 5) & $2,21 \times 10^{5} \pm 0,07$ & $5,3 \times 10^{5} \pm 0,05$ \\
Final (día 30) & $4,7 \times 10^{5} \pm 0,04$ & $9,4 \times 10^{5} \pm 0,19$ \\
\hline
\end{tabular}

metabolismo microbiano de BAL presentes en el yogur a través de la ruta metabólica de la glucólisis.

El valor final de recuento para bacterias ácido lácticas para el yogur con chocolate es similar al presentado por Shori y Baba (2012), reportando para un yogur comercial elaborado con leche de vaca un valor de $1,4 \times 10^{6}$ UFC/ $\mathrm{mL}$ al día 21 del almacenamiento. Este valor es cercano al mostrado en la tabla 2 en el yogur con chocolate $4,88 \times 10^{5} \mathrm{UFC} / \mathrm{mL}$.

\section{CONCLUSIONES}

Este estudio mostró que la adición de 6\% de chocolate al yogur tuvo comportamiento similar en comparación con el tratamiento al que se adicionó $10 \%$ de sacarosa durante el tiempo de almacenamiento. Lo anterior se evidenció en resultados de $\mathrm{pH}$ y acidez típicos para un yogur comercial con características propias. Los valores de sinéresis disminuyeron durante el almacenamiento favoreciendo así características sensoriales las cuales fueron sobresalientes resaltándose el sabor, color y textura. El análisis proximal indicó un aumento de valores de proteína, fibra y grasa respecto al yogur con sacarosa. Los valores de conteo de bacterias ácido lácticas en el yogur que contenía chocolate indicaron un aumento respecto al yogur con sacarosa, lo anterior indica que esta sustancia estimuló el metabolismo de las bacterias acido lácticas durante el almacenamiento de yogur. Basándose en las características fisicoquímicas, sensoriales, proximales y microbiológicas se sugiere que la adición de chocolate puede ser considerado potencialmente un ingrediente para elaboración de yogur.

\section{AGRADECIMIENTOS}

El autor expresa sus agradecimientos a la Dirección de Investigaciones-DIN de la Universidad Pedagógica y Tecnológica de Colombia por su apoyo para la divulgación de estos resultados. 


\section{REFERENCIAS}

Achanta, K., Kayanush, J., Aryana, J. and Boeneke, C. 2007. Fat free plain set yogurts fortified with various minerals. LWT 40:424-429.

Adolfsson, O., Meydani, S. and Russell, R. 2004. Yogurt and gut function. American Journal Clinical Nutrition 80:245-256.

A.O.A.C. (Association of Official Analytical Chemists). 1990. Official Methods of Analysis. Virginia, p1000-1050.

Blanco, S., Pacheco, E. y Fragenas, N. 2006. Evaluación física y nutricional de un yogurt con frutas tropicales bajo en calorías. Revista Facultad Agronomía. Maracay-Venezuela 32:131-144.

Briceño, A., Martínez, R. y García, K. 2001. Viabilidad y actividad de la flora láctica (streptococcus salivarius ssp. thermophilus y lactobacillus delbrueckii ssp. bulgaricus) del yogurt en Venezuela. Acta Científica Venezolana 52:46-54.

Charoenrein, S., Tatirat, O. and Muadklay, J. 2008. Use of centrifugation-filtration for determination of syneresis in freezethaw starch gels. Carbohydrate Polymers 73:143-147.

Díaz, B., Sosa, M. y Vélez, J. 2004. Efecto de la adición de fibra y disminución de grasa en las propiedades fisicoquímicas del yogurt. Revista Mexicana de Ingeniería Química 3:287-305.
Elli, M., Callegari, M., Ferrari, S., Bessi, E., Cattivelli, D., Soldi, S., Morelli, L y Goupil, N. 2006. Antoine J. Survival of Yogurt Bacteria in the Human Gut. Applied and Environmental Microbiology 72:5113-5117.

Erdem, O., Gültekin, M., Berktas, I., Ersan, S., Tuna, E., Karadag, A., Özçelik, B., Günes, G. and Cutting, S. 2014. Development of a novel synbiotic dark chocolate enriched with Bacillus indicus HU36, maltodextrin and lemon fiber: Optimization by response surface methodology. LWT - Food Science and Technology 56:187-193.

Fadela, C., Abderrahim, F and Ahmed, B. 2009. Physico-Chemical and rheological properties of yogurt manufactured with ewe's milk and skim milk. African Journal of Biotechnology 8:1938-1942.

Gutiérrez, A. 2002. Chocolate, Polifenoles y Protección a la Salud. Acta Farm. Bonaerense 21:149-152.

Hassan, A. and Amjad I. 2010. Nutritional evaluation of yoghurt prepared by different starter cultures and their physiochemical analysis during storage. African Journal of Biotechnology 9:29132917.

Hui, Y. 1993. Dairy Science and Technology Handbook. Vol. 2: Product manufacturing. VCH publishers, p1-53.

Hussain, I., Rahman, A. and Atkinson N. 2009. Quality comparision of probiotic 
and natural yogurt. Pakistan Journal of Nutrition 8:9-12.

Isanga, J. and Zhang, G. 2009. Production and evaluation of some physic-chemical parameters of peanut milk yoghurt. LWT - Food Science and Technology 42:1132-1138.

Kailasapathy, K., Harmstorf, I. y Phillips, M. 2008. Survival of Lactobacillus acidophilus and Bifidobacterium animalis ssp. lactis in stirred fruit yogurts. Food Science and Technology 41:1317-1322.

Kumar, P and Mishra, N. 2004. Yoghurt powder-a review of process technology, storage and utilization. Food and Bioproducts Processing 82:133-142.

Lubbers, S., Decourcelle, N., Vallet, N. and Guichard, E. 2004. Flavor release and rheology behaviour of strawberry fatfree stirred yogurt during storage. Journal Agricultural Food Chemistry 52:30773082.

Nilva, P., Oliveira, E and Cadore, S. 2006. Study of the mineral content of chocolate flavoured beverages. Food Chemistry 95:94-100.

Noni, I., Pellegrino, L and Masotti, F. 2004. Survey of selected chemical and microbiological characteristics of (plain or sweetened) natural yoghurts from the Italian market Lait 84:421-433.

Olson, D. and Aryana, J. 2008. An excessively high Lactobacillus acidophilus inoculation level in yogurt lowers product quality during storage. LWT 41:911-918.

Parra, R., Martínez, C. y Espinosa, J. 2011. Comportamiento fisicoquímico de stevia, fructosa, dextrosa y lactosa como endulzantes a diferentes concentraciones durante el tiempo de incubación en la elaboración de yogurt entero. Bistúa: Revista de la Facultad de Ciencias Básicas 9:15-20.

Parra, R y Medina, O. 2011. Propiedades físicas- químicas de yogurt tipo entero: efecto de la adición de goma xantana y goma guar en la incubación. Revista Ciencia en Desarrollo 3:163-177.

Parra, R. 2012. Yogurt en la salud humana. Revista lasallista de investigación 9:160175.

Peng, Y., Serra, M., Home, D. and Lucey, J. 2009. Effect of fortification with various types of milk protein on the rheological properties and permeability of nonfat set yogurt. Journal of Food Science 74:666673.

Ruiz, J. y Ramírez, M. 2009. Elaboración de yogurt con probióticos (Bifidobacterium spp. y Lactobacillus acidophillus) e inulina. Revista Facultad Agronomía (LUZ) 26:223-242.

Sahan, N., Yasarb, K. and Hayaloglu, A. 2008. Physical, chemical and flavour quality of non-fat yogurt as affected by a $\beta$-glucanhydrocolloidal composite 
during storage. Food Hydrocolloids 22:12911297.

\section{Saint-Eve, A., Lévy, C., Moigne, M., Ducruet, V} and Souchon, I. 2008. Quality changes in yogurt during storage in different packaging materials. Food Chemistry 110:285-293.

Salvatierra, M., Molina, A., Gamboa, M y Arias, M. 2004. Evaluación del efecto de cultivos probióticos presentes en yogurt sobre Staphylococcus aureus y la producción de termonucleasa. Archivos Latinoamericanos de Nutrición 54:298302.

Sodini, I., Montella, J. and Tong, P. 2005. Physical properties of yogurt fortified with various commercial whey protein concentrates. Journal Science Food Agriculture 85:853-859.

Shori, A and Baba, A. 2012. Viability of lactic acid bacteria and sensory evaluation in Cinnamomumverum and Allium sativum-bio-yogurts made from camel and cow milk. Journal of the Association of Arab Universities for Basic and Applied Sciences 11:50-55.
Tinoco, H y Ospina, D. 2010. Análisis del proceso de deshidratación de cacao Para la disminución del tiempo de secado. RevistaEIA 13:53-63.

Yanus, R., Sela, H., Borojovich, E., Zakon, Y., Saphier, M., Nikolski, A., Gutflais, E., Lorber, A and Karpas, Z. 2014. Trace elements in cocoa solids and chocolate: An ICPMStudy. Talanta 119:1-4.

Valenzuela, A. 2007. El chocolate, un placer saludable. Revista Chilena de Nutrición 34:1-21.

Zahoor, T., Rahman, S. and Farooq, U. 2003. Viability of Lactobacillus bulgaricusas Yoghurt Culture Under Different Preservation Methods. International Journal of Agriculture and Biology 5:4648.

Zare, F., Boye, J. and Orsat, V. 2011. Microbial, physical and sensory properties of yogurt supplemented with lentil flour. FoodResearch International 44:24822488.

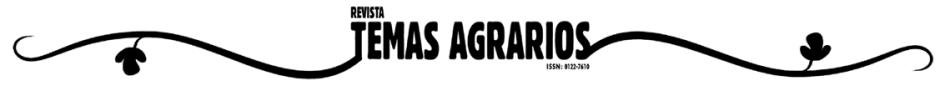

